\title{
Structured Product Labeling Flavor
}

National Cancer Institute

\section{Source}

National Cancer Institute. Structured Product Labeling Flavor. NCI Thesaurus. Code C73338.

A characteristic of a medicinal product, specifying the most predominant flavor. Flavor is not an FDA specification for the names of specific flavors that may appear as inactive product ingredients in labeling. 